\title{
LINEAR AIRWAY DIMENSIONS IN CHILDREN: INCLUDING THOSE WITH CLEFT PALATE
}

\author{
G.A.R. Morgan and D.J. Steward
}

\begin{abstract}
Linear airway dimensions from incisor teeth to vocal cords were measured from radiographs. Normal children were slightly taller and heavier than children being treated for cleft palate and had significantly longer upper airway dimensions. Tracheal length was measured in 50 normal children breathing spontaneously under general anaesthesia and was found to correlate best with body weight. Strong positive correlation with height was also found. Data from normal children in these two studies were used to calculate the distance from lips to mid-trachea to determine optimal length for a tracheal tube. Previously published data on airway lengths in children are reviewed.
\end{abstract}

KEY WORDS: AIRWAY, anatomy; linear dimensions, children.

THE LENGTH of the trachea in infants and children is short, thus precise placement of the tip of a tracheal tube is essential if bronchial intubation or accidental extubation are to be avoided. This is particularly important if the head will be flexed or extended during the surgical procedure. ' The increasing popularity of the pre-formed, pre-shaped tracheal tube, as for example that designed by Ring, Adair, and Elwyn, ${ }^{2}$ has made it imperative that tracheal tube length should match the dimensions of the airway as closely as possible. There is a lack of precise knowledge of the normal dimensions of the airway in living children. Several reported studies are based on post-mortem measurements. Furthermore, some children requiring surgery for correction of congenital anomalies may be morphologically smaller than their unaffected peers and the possibility that they may have smaller linear airway dimensions has not been fully investigated. This would be especially important in patients having head and neck

G.A.R. Morgan, M.B., B.S., F.F.A.R.C.S. Fellow in Anaesthesia; D.J. Steward M.B., B.S., F.R.C.P.(C) Anaesthetist-in-Chief; Department of Anaesthesia, The Hospital For Sick Children, Toronto, Ontario, Canada. Department of Anaesthesia, University of Toronto, Canada.

Reprint Requests to: Dr. D.J. Steward, Department of Anaesthesia, The Hospital for Sick Children, 555 University Avenue, Toronto, Ontario M5G 1 X8.

Dr. Morgan's Present Address: Senior Registrar in Anaesthesia, Bristol Royal Infirmary, Bristol BS2 BHW, Avon, England.

Can. Anaesth. Soc. J., vol. 29, no. 1, January 1982 surgery, for example, repair of cleft palate when a pre-formed tracheal tube may be used.

Two studies were undertaken:

Study 1. From pre-existing radiographs of the head and neck, we have measured upper airway dimensions of two groups of twenty children who were $\mathrm{x}$-rayed at intervals between the ages of 4 and 16 years. The dimensions measured in the radiographic study are shown in Figure 1. They were the distances from: (a) Submentum to anterior border of the lips, (b) Lips to teeth, (c) Incisor teeth to anterior border of C2 vertebra, (d) $\mathrm{C} 2$ vertebra to vocal cords.

Two angles were also measured, $\alpha$ - between (a) and (c) and $\beta$ - between (b) and (d).

Two groups were studied. The first were normal children who had taken part in a Growth and Development Study. * The second group had been treated for cleft palate at the Hospital for Sick Children. Each child had been $x$-rayed at approximately yearly intervals over a period of up to 13 years. Two hundred and six radiographs from the normal children were measured and 114 from the children with cleft palate. The number of radiographs measured in each group is shown in Table I. The weights and heights of the children on the date of $\mathrm{x}$-ray were obtained from their hospital records. The children were grouped by age to the year nearest their age on the date of $x$-ray. The dimensions measured from the radiographs were reduced by a factor of

*Burlington Growth Centre, Faculty of Dentistry, University of Toronto, Toronto, Ontario, Canada. 


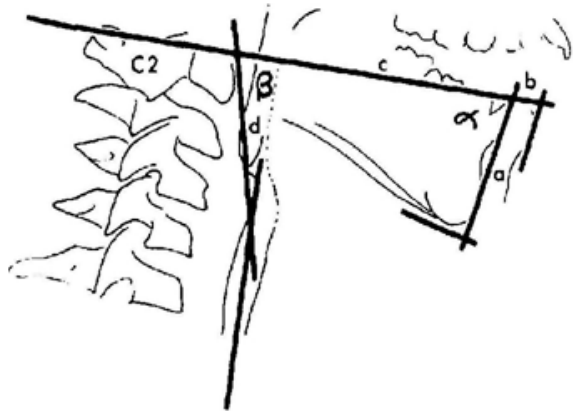

FIGURE 1 The dimensions of the upper airway measured from the radiographs and bronchoscopies.

0.1 to correct for magnification during standardized radiography. The mean values of the dimensions measured in normal children and those with cleft palate were compared at each age using Student's t-test. The comparison was omitted for groups of less than four children of either sex in either group at a particular age. The mean airway dimensions were plotted graphically to demonstrate variation with age, weight and height.

Study 2. The length of the trachea from the vocal cords to the carina was measured during bronchoscopy of 50 children breathing spontaneously under general anaesthesia. The method of measurement is shown in Figure 2. The tip of the bronchoscope is passed from the carina to the vocal cords and the tracheal length (B) measured as the length of bronchoscope (A) withdrawn

TABLE I

Number of Radiographs Measured in Normat. Children and Children with Cleft Palate

\begin{tabular}{rccccc}
\hline & \multicolumn{2}{c}{ Males } & & \multicolumn{2}{c}{ Females } \\
\cline { 2 - 3 } \cline { 5 - 6 } Age & Normal & $\begin{array}{c}\text { Cleft } \\
\text { palate }\end{array}$ & & Normal & $\begin{array}{c}\text { Cleft } \\
\text { palate }\end{array}$ \\
\hline 3 & 0 & 0 & 5 & 0 \\
4 & 7 & 0 & 9 & 0 \\
5 & 7 & 8 & 9 & 7 \\
6 & 6 & 6 & 8 & 0 \\
7 & 9 & 8 & 7 & 7 \\
8 & 10 & 5 & 9 & 5 \\
9 & 10 & 6 & 10 & 4 \\
10 & 9 & 5 & 7 & 4 \\
11 & 9 & 5 & 8 & 7 \\
12 & 7 & 0 & 9 & 0 \\
13 & 9 & 6 & 10 & 9 \\
14 & 7 & 0 & 9 & 3 \\
15 & 4 & 5 & 0 & 8 \\
16 & 5 & 0 & 7 & 0 \\
17 & & & & 6 \\
Totals & 99 & 54 & 107 & 60 \\
\hline
\end{tabular}

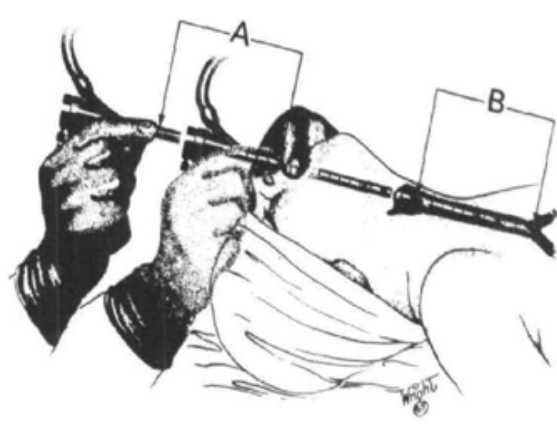

Figure 2 Method used to measure tracheal length in a child.

from the mouth. ${ }^{3}$ Tracheal length was plotted against age, height and weight of the patients. From data combined from the two studies, the length of the airway from the teeth to the midpoint of the trachea was calculated for normal living males and females at ages from 3-16 years.

\section{RESULTS}

\section{Study 1}

Those children with cleft palate were generally of lower mean weight than their normal peers, but no statistically significant difference in weight could be detected at any age in the males, and in the females only at ages seven and nine years. The mean heights of those children with cleft palate were shorter at all ages than their normal peers. However, no statistically significant difference could be detected at any age between the normal children and those with cleft palate.

The measurements taken from the radiographic study were those which follow the course of a tracheal tube. These are the distances from the lower incisor teeth to the pharyngeal mucosa overlying $\mathrm{C} 2$ vertebra, and from this point to the vocal cords. The mucosa overlying $\mathrm{C} 2$ is in fact closely applied to the bone and so this easily located landmark was chosen for the purpose of measurement.

Figures 3 and 4 show the distance from the incisor teeth to the second cervical vertebra plotted against age in the males and the females. The mean distance from the incisor teeth to $\mathrm{C} 2$ vertebra was greater in normal males than in those with cleft palate at all ages. A statistically significant difference was demonstrated in all of the seven age groups with sufficient data. This dimension was also greater in normal females 


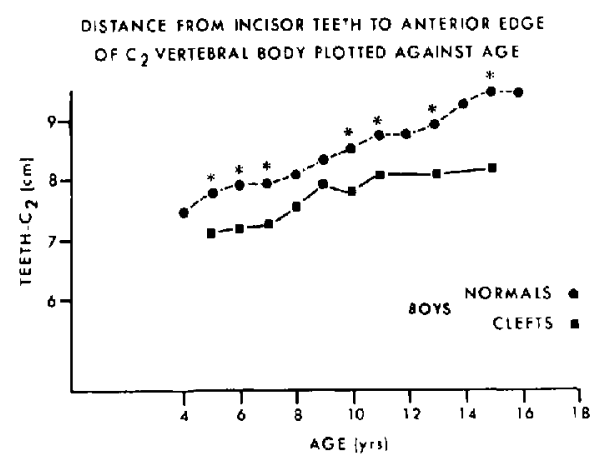

* SIGNIFICANT differenCE

FIGURE 3 Distance from incisor teeth to anterior edge of $\mathrm{C} 2$ vertebral body plotted against age in boys.

DISTANCE FROM INCISOR IEETH TO ANTERIOR EDGE OF $C_{2}$ VERTEBRAL BOOY PLOTIED AGAINST AGE

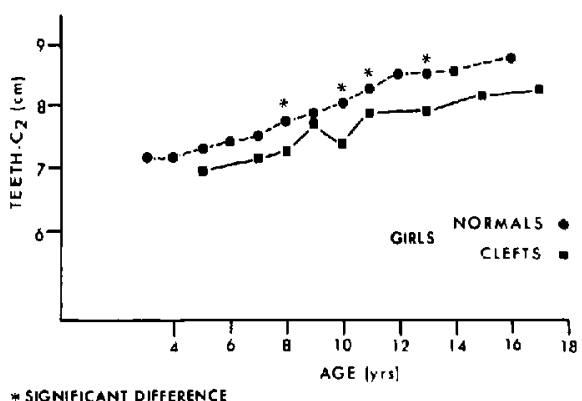

FIGURE 4 Distance from incisor teeth to anterior edge of $\mathrm{C} 2$ vertebral body plotted against age in girls.

than in those with cleft palate and showed a statistically significant difference in four of the seven age groups tested.

Figures 5 and 6 show the distance from $\mathrm{C} 2$ to the vocal cords plotted against age in the males and females. The mean value was greater in normal males and females than in their age peers with cleft palate. Of the males, statistically significant difference was demonstrated in seven of nine groups tested. In the females three of the seven groups tested showed a statistically significant difference.

No other dimensions measured from the radiographs showed significant differences: The mean distance from the lips to the teeth was between 1.0 and $1.5 \mathrm{~cm}$ at all ages. The mean distance from submentum to lips increased from 4.4 to $5.5 \mathrm{~cm}$ over the age range studied. The two angles measured also tended to increase over the range of ages. Angle $\alpha$ (at the teeth)

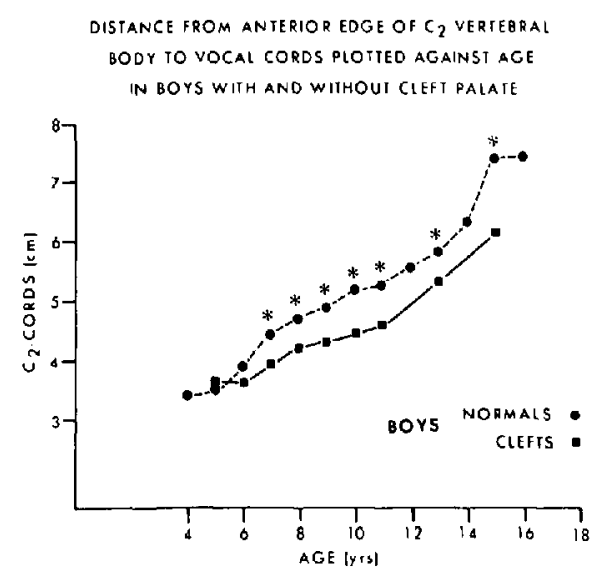

* SIGNIFICANT DIFFERENCE

FIGURE 5 Distance anterior edge of $\mathrm{C} 2$ vertebral body to vocal cords plotted against age in boys with and without cleft palate.

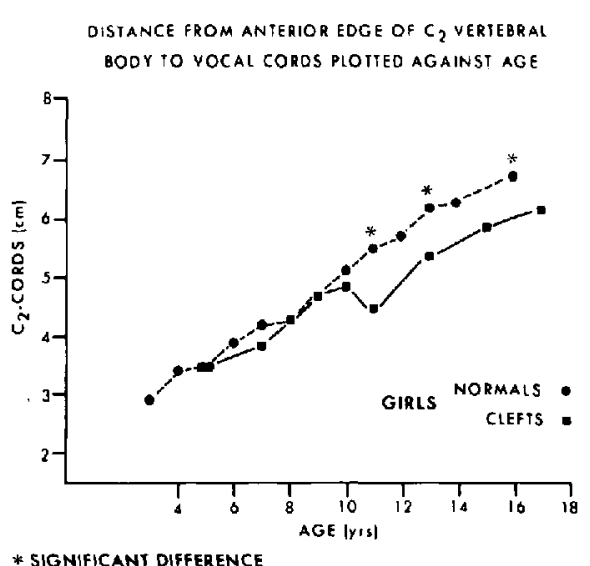

FIGURE 6 Distance anterior edge of $C 2$ vertebral body to vocal cords plotted against age in girls with and without cleft palate.

increased from $65^{\circ}$ to $75^{\circ}$ and angle $\beta$ (at the posterior pharynx) from $75^{\circ}$ to $85^{\circ}$.

The length of the airway from the incisor teeth to the vocal cords was expressed as the combined dimensions (teeth to $\mathrm{C} 2)+(\mathrm{C} 2$ to vocal cords), and was plotted against height for males and females with and without cleft palate (Figure 7). A strong positive correlation was seen in all four groups. The combined dimensions also correlate well with body weight (Figure 8), all groups showing a similar relationship. The regression equations for the combined dimensions plotted against height and weight are shown in Table II. 
TABLE II

Regression Equations for the Graphs (teeth- $\left.\mathrm{C}_{2}\right)+\left(\mathrm{C}_{2}-\right.$ cord) Plotted Against Height aNd WEIGHT IN THE ChILDREN StUdied

\begin{tabular}{lcc}
\hline \multicolumn{1}{c}{ Group } & \multicolumn{1}{c}{ Height } & Weight \\
\hline Normal males & $\mathrm{Y}=-9.228+10.737 \mathrm{X}$ & $\mathrm{Y}=8.755+0.131 \mathrm{X}$ \\
Cleft males & $\mathrm{Y}=-20.357+12.556 \mathrm{X}$ & $\mathrm{Y}=8.576+0.12 \mathrm{X}$ \\
Normal females & $\mathrm{Y}=-27.302+12.523 \mathrm{X}$ & $\mathrm{Y}=8.721+0.124 \mathrm{X}$ \\
Cleft females & $\mathrm{Y}=-30.57+13.35 \mathrm{X}$ & $\mathrm{Y}=8.824+0.664 \mathrm{X}$ \\
\hline
\end{tabular}

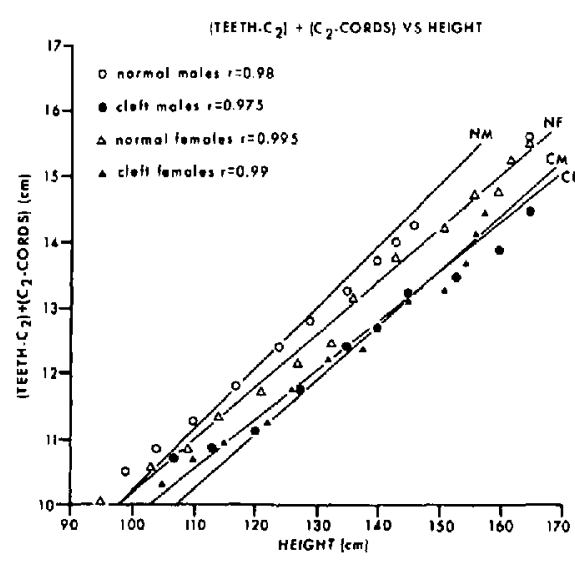

FIGURE 7 Combined dimensions (teeth-C2) + (C2-Cords) plotted against height in children with and without cleft palate.

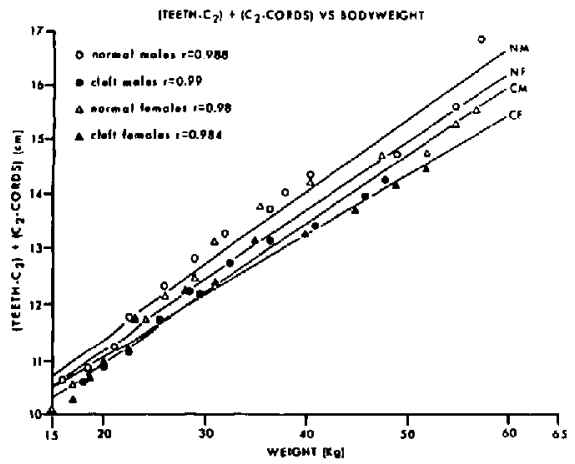

FIGURE 8 Combined dimensions (teeth-C2) + (C2-Cords) plotted against bodyweight in children with and without cleft palate.

\section{Study 2}

From the bronchoscopic study, tracheal length correlated best with body weight, ( $\mathrm{Y}=$ $5.624+0.166 \mathrm{X})$, with a correlation coefficient of 0.908 (Figure 9). Strong positive correlation was also demonstrated between tracheal length and height. The correlation coefficient with

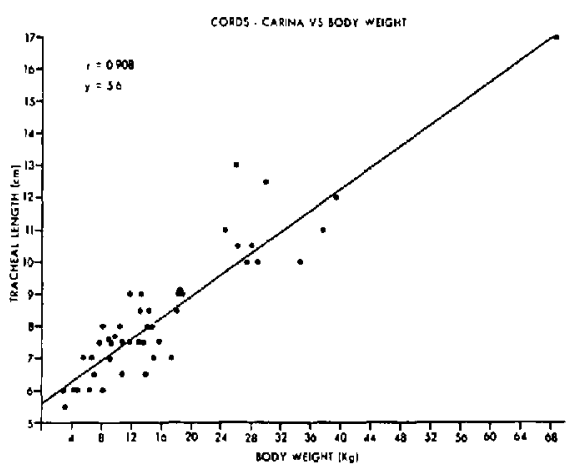

FIGURE 9 The relationship of the distance from vocal cords to carina with body weight in the children bronchoscoped.

height was 0.881 (not shown) and the regression equation $\mathrm{Y}=0.059 \mathrm{X}$. However, this equation represented a regression line that did not pass through the majority of points in the graph and is possibly misleading. If values of four points are omitted, as representing wide variations from the mean values, the regression equation then recalculated is $\mathrm{Y}=3.411+0.052 \mathrm{X}$. This is represented by a line which passes more evenly through the sample and has a correlation coefficient of 0.863 .

We have combined the data from the radiographic study in the normal children and the bronchoscopic study to calculate the length of the airway from the teeth to the midpoint of the trachea. This is intended as a guide to airway length for the correct placement of tracheal tubes. The linear relationship of this distance with age is shown for normal males and females in Figure 10. The regression equations for males and females were $\mathrm{Y}=11.946+0.725$ and, $\mathrm{Y}=$ $11.857+0.664 \mathrm{X}$ respectively. Figure 11 shows the relationship between the distance from the teeth to the midpoint of the trachea with the height of the patients, $Y=1.622+0.127 X$ for males, $Y=2.346$ for females. Figure 12 shows 
TABLE III

Summarized Data from Five Studies of Tracheal length Approximated to Patients' Age where NOT STATED IN ORJGINAL WORK

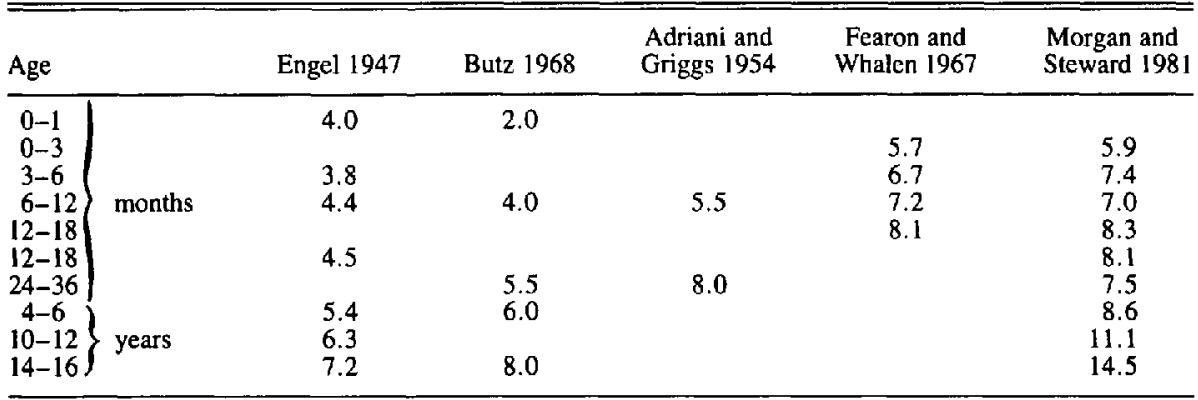

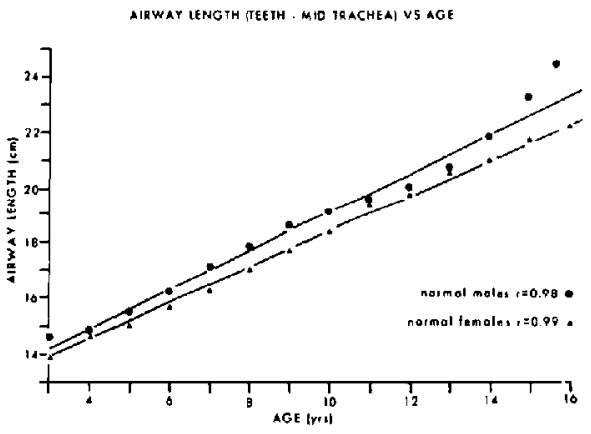

Figure 10 Airway length from incisor teeth to midtrachea and age in normal children.

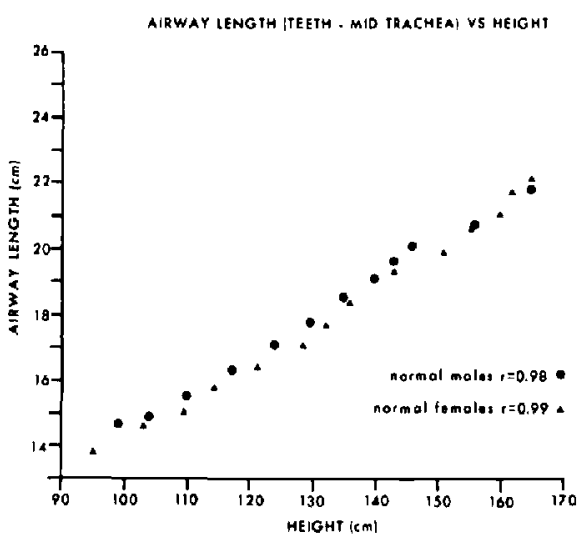

Figure 11 Airway length from incisor teeth to midtrachea and the height of normal children.

the relationship of this dimension with body weight.

Strong positive correlation was demonstrated between the distance from the teeth to the

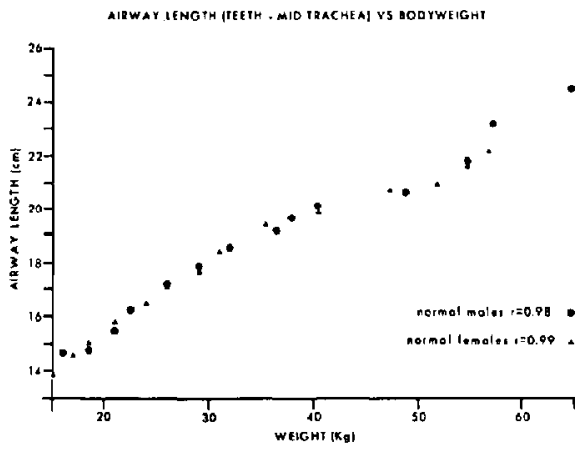

FIGURE 12 Airway length from incisor teeth to midtrachea and the weight of the normal children.

midpoint of the trachea and the age, height, and weight of the children studied. From this data we have produced three equations to calculate the length of the airway from the incisor teeth to the midpoint of the trachea:

Airway Length (teeth - mid trachea $)=14.5$
$+[($ Age -3$) \times 0.6]$ for ages $3-14$ years

or

$$
\begin{aligned}
& =\frac{\text { Height }(\mathrm{cm})}{10}+5 \mathrm{~cm} \text { for all ages } \\
& =12+\frac{\text { Weight }(\mathrm{kg})}{5} \text { for all ages }
\end{aligned}
$$

We consider the equation for height to be the easiest and most reliable to use for reference.

Tables IV and V show a synopsis of the upper airway dimension in the normal males and females we have studied. 

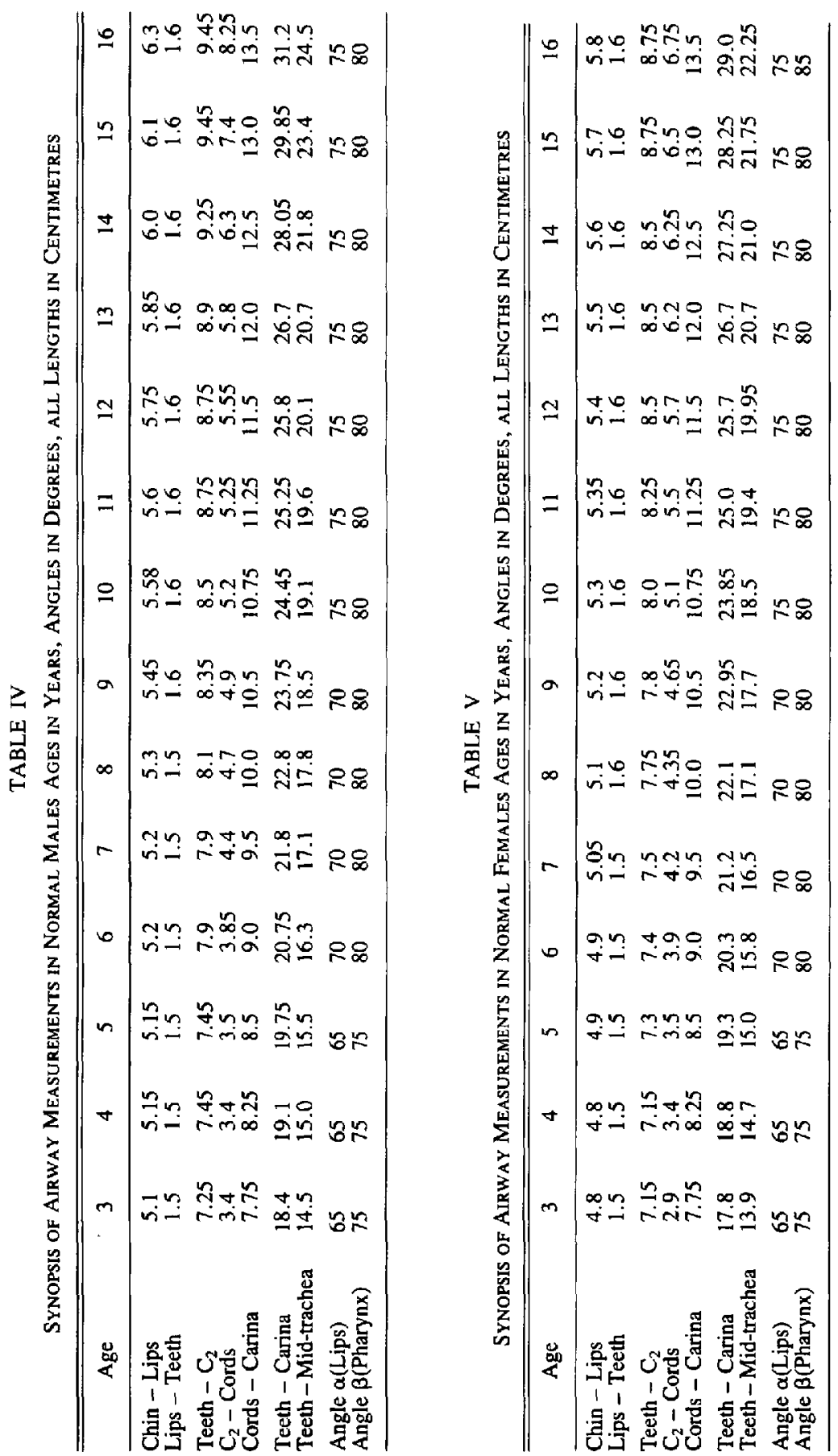


\section{Discussion}

The use of pre-existing radiographs has permitted a longitudinal study over a period of years of the development of the airway in a group of living subjects. Possible inaccuracies include error due to magnification of the radiographic image, poor visualization of soft tissue landmarks such as the vocal cords and inconsistency of position of the subject. In addition, the patient's height and weight on the date of X-ray may not always be available. We attempted to reduce errors from such sources to a minimum, and measurements from many radiographs of children being treated for cleft palate were excluded from the study for these reasons. As a result, at some ages there was insufficient data for a statistical comparison to be made between normal children and those being treated for cleft palate. However, the continuity in such a study does provide some homogeneity of samples from age to age and this compensates for small sample sizes. We were able to demonstrate a statistically significant difference between the upper airway measurements in normal children and in those with cleft palate.

Currently available information on linear airway dimensions in children is inconsistent and is therefore not very helpful for clinical practice. It has been obtained mainly from post-mortem studies which show tracheal lengths shorter than those measured in this study of living subjects. Reasons suggested for this include tissue shrinkage or distortion with death and the elevated position of the diaphragm in the supine cadaver. Further shortening of the trachea during removal of the thoracic contents may occur.

Engel ${ }^{4}$ in a post-mortem study, made Wood's metal casts of the tracheo-bronchial tree before the chest was opened. These were measured following their removal and related to the age of the child. Adriani and Griggs ${ }^{5}$ measured tracheal length in a post-mortem study of children under three years of age. The specimens were fresh and unfixed but it is not stated whether or not they were removed from the body. Their results were related to the weights of the children which makes comparison with Engel's study difficult. But $^{6}$ studied specimens removed from the body, and then photographed. A scale included in the photographs served as a reference from which measurements were made. A comparison of tracheal lengths obtained from all these studies can be seen in Table III. Fearon and
Whalen's $s^{3}$ study of tracheal lengths in living infants included only those from birth to 18 months of age. Their results agree with ours measured in the same age group. Compared with post-mortem studies, our results and those of Fearon and Whalen demonstrate longer tracheal lengths at all ages.

Several attempts have been made to measure the length required for a tracheal tube. Measurement of airway length from teeth to carina using a rigid bronchoscope ${ }^{7}$ takes no account of the shape of the airway. Schellinger, ${ }^{8}$ in a post-mortem study, used curved tracheal tubes to measure airway length from carina to nares or incisor teeth. Adriani and Griggs measured tracheal length from cords to carina for the purpose of designing a tracheal tube. However, their tube possessed a shoulder similar to that of the Cole ${ }^{9}$ tube, and the portion of the tube above the cords was simply cut to the correct length. The flexibility of the rubber allowed the tube to conform to the shape of the airway. While some tracheal tubes may be cut in this manner to suit the airway dimensions of the patient, preformed tracheal tubes are manufactured with a fixed length and shape. When such tubes are used, the position of the tracheal tip depends upon both the length and the shape of the airway. Unless the shape of the tube conforms well to that of the airway, undue pressure may be exerted on adjacent structures. Unless the length of the tube is well matched to that of the airway, bronchial intubation or accidental extubation may occur, especially in the smaller patients. Tracheal tubes should be designed with reference to the dimensions of the upper airway to ensure accurate placement of the tip at the midpoint of the trachea.

\section{CONCLUSIONS}

We have measured the linear dimensions of the upper airways in children from 3-16 years of age. The distance from vocal cords to the carina in normal children correlated best with body weight, but strong positive correlation was also demonstrated with height. Children with cleft palate may be slightly smaller in height and weight than their normal age peers. Their upper airway dimensions, however, still correlate well with their heights and weights at all ages.

In normal children it may be acceptable to use age as a guide to correct length of a tracheal tube. We suggest, however, that the height or weight 
of the child may be of more value in this assessment, especially in the practice of paediatric anaesthesia when sick children who may be under or over developed for their age present for surgery.

\section{ACKNOWLEDGEMENTS}

The authors acknowledge the kind assistance of Dr. D.P. Mitchell and Dr. B. Fearon and other members of the Department of Oto-RhinoLaryngology of The Hospital For Sick Children.

The co-operation of Dr. I. Munro, Division of Plastic Surgery, Dr. Bruce Ross, Department of Dentistry, The Hospital For Sick Children, and Dr. F. Popovitch, School of Dentistry, University of Toronto, is gratefully recognized.

Figure 2 is reproduced from the Annals of Otology, Rhinology and Laryngology with permission of the publisher and the authors.

\section{REFERENCES}

1. Bosman, Y.K. \& Foster, P.A. Endotracheal intubation and the head posture in infants. South African Med. J. 52: 71-73, 1977.

2. Ring, W.H., Adair, J.C. \& Elwyn, R.A. A new endotracheal tube. Anaesthesia and Analgesia. Current Researches 54: 273-274, 1975.

3. Fearon, B. \& Whalen, J.S. Tracheal dimensions in the living infant. Annals of Otology, Rhinology and Laryngology 76: 964-974, 1967.

4. ENGEL, S. The child's lung. Developmental Anatomy, Physiology and Pathology. Amold, London, 1947.

5. ADRIANI. M.D. \& GRIGGS, T.S. An improved endotracheal tube for paediatric use. Anesthesiology 15: 566-570, 1954.

6. BuTz, R.O. Jr. Length and cross section growth patterns in the human trachea. Pediatrics 42: 336-341, 1968.

7. JACKSON, C. Tracheobronchoscopy, esophagoscopy and gastroscopy. Laryngoscope 17: 65, 1907.

8. SChellinger, R.R. The length of the airway to the bifurcation of the trachea. Anesthesiology 25 : $169-172,1964$.

9. Cole, F. A new endotracheal tube for infants. Anesthesiology 6: 87-88, 1945.

\section{RÉsumé}

Nous avons mesuré sur des radiographies la distance linéaire entre les dents (incisives) et les cordes vocales. Les enfants normaux étaient de taille et de poids légèrement supérieurs à ceux traités pour fissure palatine et leurs distances entre les dents et les cordes vocales étaient également supérieures de façon significative, à celles mesurées chez les enfants présentant une fissure palatine. Nous avons aussi mesuré la longueur de la trachée chez 50 enfants normaux sous anesthésie générale et en respiration spontanée. C'est le poids de l'enfant qui présentait la meilleure corrélation avec la longueur de la trachée; il y avait également une excellente corrélation entre la taille et la longueur trachéale. A partir des résultats de ces deux mesures, nous avons calculé les distances entre les incisives et un point situé au milieu de la trachée en vue d'établir les longueurs optimales des tubes trachéaux utilisés en pédiatrie. La formule la plus facile et la plus fiable est la suivante:

$$
\text { Distance en cm entre les incisives et la mi-tranchée }=\frac{\text { taille }(\mathrm{en} \mathrm{cm})}{10}+5 \mathrm{~cm}
$$

Les valeurs publiées précédemment sur ce sujet sont revues et discutées. 